\title{
Review of the Cervical Cancer Burden and Population-Based Cervical Cancer Screening in China
}

\author{
Jiangli Di, Shannon Rutherford, Cordia Chu*
}

\begin{abstract}
Cervical cancer continues to be a serious public health problem in the developing world, including China. Because of its large population with geographical and socioeconomic inequities, China has a high burden of cervical cancer and important disparities among different regions. In this review, we first present an overview of the cervical cancer incidence and mortality over time, and focus on diversity and disparity in access to care for various subpopulations across geographical regions and socioeconomic strata in China. Then, we describe population-based cervical cancer screening in China, and in particular implementation of the National Cervical Cancer Screening Program in Rural Areas (NACCSPRA) and the challenges that this program faces. These include low screening coverage, shortage of qualified health care personnel and limited funds. To improve prevention of cervical cancer and obtain better cancer outcomes, the Chinese government needs to urgently consider the following key factors: reducing disparities in health care access, collecting accurate and broadly representative data in cancer registries, expanding target population size and increasing allocation of government funding for training of personnel, improving health education for women, enhancing quality control of screening services and improving a system to increase follow up for women with positive results.
\end{abstract}

Keywords: Cervical cancer burden - China - population-based cervical cancer screening - program

Asian Pac J Cancer Prev, 16 (17), 7401-7407

\section{Introduction}

Cervical cancer continues to be the most common cancer among Chinese women. Because of its large population with significant regional and socioeconomic disparities, substantial inequity in financial resources, infrastructure, health care staff, and access to health care, China carries a heavy global burden of cervical cancer, and significant disparities exist in cervical cancer burden across different regions. In order to reduce the gap in cervical cancer burden between different regions, the Chinese government implemented several important measures, including the implementation of the National Cervical Cancer Screening Program in Rural Areas since 2009.

This review will describe the cervical cancer burden in China, analyse the possible factors influencing disparities in cervical cancer burden among different regions, the state of the national program, and then describe the major challenges to more effective implementation of this program. Finally it provides recommendations to improve the delivery and outcomes for cervical cancer screening and reduce the inequalities in rates that exist across different regions. We hope that this review triggers a considered debate among policy makers and contributes to improved measures for cervical cancer prevention and control in China.

\section{Cervical cancer burden in China}

Globally, cervical cancer accounts for almost $12 \%$ of all female cancers, making it the fourth most common female cancer in the world. According to IARC projections, 528,000 new cases occurred in 2012 and in the same year, cervical cancer was responsible for 266,000 deaths, accounting for $7.5 \%$ of all female cancer deaths. Cervical cancer has become the leading cause of cancer death among women and around $87 \%$ of cervical cancer deaths occur in developing countries (IARC, 2012b).

China accounts for approximately one fifth of the world's population, and its cervical cancer burden has a substantial effect on global estimates of the current and future burden of the disease. A recent estimate by GLOBOCAN suggests that the number of new cervical cancer cases in China was 61,691 in 2012 (IARC, 2012b), accounting for $12 \%$ of new cases of cervical cancer in the world. The most recent survey suggests that the number of new cases is projected to rise to 93,500 in 2030 and reach 186,600 in 2050 (Shi et al., 2012). Furthermore, 29,526 women died of the disease in 2012 in China, accounting for $11 \%$ all cervical cancer deaths worldwide (IARC, 2012b). The ratio of the number of cervical cancer deaths to the number of new cases was 0.45 in 2012, compared with 0.65 in Sub-Saharan Africa, 0.53 in less developed regions and 0.33 in more developed regions (IARC, 2012a). 
China's achievements in reducing incidence and mortality of cervical cancer have been significant. The detection rate of cervical cancer decreased from 145 per 100000 women in the 1950 s to 8.2 per 100000 women in the 1990s (MOH, 2006). However, comparison of data from 2003 to 2010 indicates that cervical cancer incidence and mortality have increased in the $21^{\text {st }}$ century (Figure 1).

A comparison of the latest Chinese Cancer Registry Annual Report (CCRAR) (2013) with the previous one (2004), identifies that although there was a steady incidence trend of 7.4/100,000 in rural areas from 2007 to 2009 , the national incidence has increased by $157.9 \%$ from 2003 to 2010 (NOCPC et al., 2010; NCC et al., 2012 ; 2013). Furthermore, the sharp increase in incidence from 2009 to 2010 in both rural and urban areas requires further investigation.

A comparison of 2003 and 2010 surveys (Figure 2) indicates that the national mortality rate for cervical cancer has also increased incrementally (NOCPC et al., 2008; NCC et al., 2013), with an overall increase in that period of $116.7 \%$. Similar to incidence, the mortality CASR increased rapidly from 2009 to 2010. The data shows that the increase in rate is higher in urban areas compared to rural areas.

The data for incidence and mortality of cervical cancer in China presented in this review is from the Chinese National Central Cancer Registry (NCCR). Since it was established, the number of cancer registries has increased rapidly, from the original 30 registries distributed over 18 of the 31 provinces to 216 registries across the whole nation in 2010 (NCC et al., 2013). From 2009 to 2010, the number of qualified registries and the population coverage increased sharply. There were 72 qualified registries in 2009 (covering about $6.4 \%$ of China's population), compared with 145 in 2010 (covering about $11.9 \%$ of the population) (NCC et al., 2013). Furthermore, in order to improve the quality of the registry data, in 2010 the NCCR carried out a comprehensive evaluation and surveillance of the cancer registration system, balanced the number of registries in urban and in rural areas, and distributed registries across the whole nation (NCC et al., 2013).

Although the population coverage has increased rapidly, it still remains low in contrast to the $96 \%$ coverage of registries in the USA and nearly $100 \%$ coverage in the UK (NCC et al., 2012). Besides the limitation of coverage, the quality of registration data is also deficient. The 2010 evaluation by IARC of registration data quality for cancer incidence in 5 continents found that data from only 12 registries in China was considered to be of a high enough standard for inclusion in their study (NCC et al., 2013).

The low proportion of the population covered and the poor quality of data represented in the NCCR hinders accurate data interpretation; moreover, the data reported significantly lags behind the actual situation (it can only reflect the situation of cervical cancer three years ago), so the true and timely burden of cervical cancer in China estimated solely on the basis of cancer registration data is difficult. For all these reasons, it is not clear that the sharp increase of cervical cancer incidence and mortality from 2009 to 2010 can be attributed to the rapid expansion of coverage and improved data quality and hence improved data collection and reporting, or to the implementation of the NCCSPRA in 2009 which increased resources and capacity to improve screening and hence detection and monitoring in these areas. Analysis of additional years of data will help to better understand this trend and the factors contributing to it. However, it is clear from these figures that there is an overall increasing trend in both incidence and mortality in the reporting period from 2003-2010.

Both measures of incidence and mortality for cervical cancer are unequally distributed across different regions of China, with notable differences between rural and urban areas, and eastern, central and western regions.

According to the 2013 CCRAR, in 2010, the national incidence of cervical cancer was 8.9/100,000 (Chen et al., 2014). The incidence of cervical cancer in urban areas was slightly higher $(13 \%)$ than in rural areas and it also varied among different regions of China (Table 1), with the highest incidence observed in central regions, followed by eastern and western regions (NCC et al., 2013).

The 2013 CCRAR indicates the national mortality from cervical cancer was $2.8 / 100,000$. The range in mortality among regions is smaller than that for incidence. The ratio of cervical cancer deaths to the number of new cases was 0.25 in urban areas, whereas in rural areas it was 0.3 . This phenomenon is also reflected in the eastern, central and western regions (Table 2). The mortality-toincidence ratio for eastern regions is 0.24 , compared with 0.28 in central regions and 0.34 in western regions (NCC et al., 2013).

To understand the disparities of cervical cancer burden of different areas within China, one must understand the social and economic aspects of the different regions. Urban areas are defined as where economic development, politics, and culture do not centre on agriculture (Jian et al., 2010). Eastern China, the most economically advanced of the three regions with a GDP of US\$5464 includes

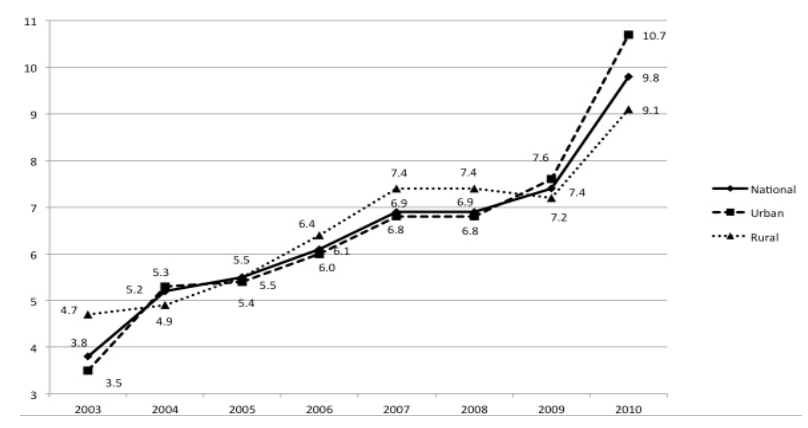

Figure 1. Trend in Cervical Cancer Incidence per 100 000, from 2003 to 2010 in China

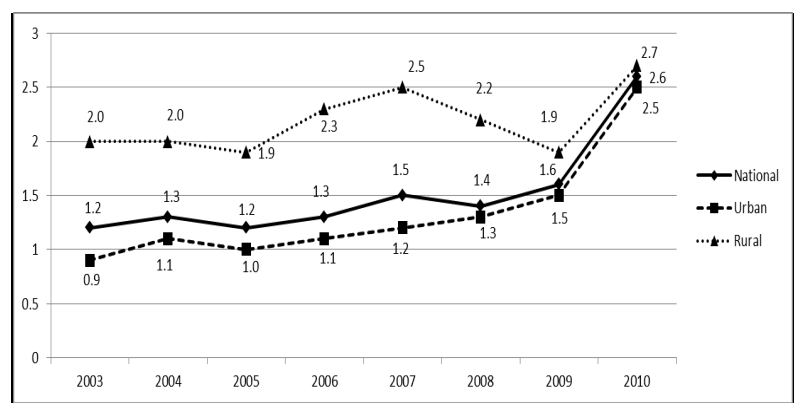

Figure 2. Trend in Mortality Rate of Cervical Cancer per 100000 , from 2003 to 2010 in China 
all of the seacoast and covers an area of 12.9 million square kilometres (Jian et al., 2010; Goss et al., 2014). Urban residents make up $64.7 \%$ of the population (NBS, 2014b). Central China, with an area of 28.2 million square kilometres, has a GDP of US\$2630 (Jian et al., 2010; Goss et al., 2014), and $48.7 \%$ of the population live in urban

Table 1. Cervical Cancer Incidence per 100,000, in China in 2010

\begin{tabular}{lccc}
\hline & $\begin{array}{c}\text { Cases } \\
\text { (Number) }\end{array}$ & $\begin{array}{c}\text { CASR } \\
(1 / 100000)\end{array}$ & $\begin{array}{c}\text { WASR } \\
(1 / 100000)\end{array}$ \\
\hline National & 76884 & 9.84 & 8.86 \\
Urban areas & 42173 & 10.7 & 9.52 \\
Rural areas & 34711 & 9.08 & 8.27 \\
Eastern regions & 30146 & 9.17 & 8.22 \\
Central regions & 29345 & 11.51 & 10.44 \\
Western regions & 17393 & 8.81 & 7.9 \\
\hline
\end{tabular}

Table 2. Mortality of Cervical Cancer per 100,000, in China in 2010

\begin{tabular}{lccc}
\hline & $\begin{array}{c}\text { Cases } \\
(\text { Number })\end{array}$ & $\begin{array}{c}\text { CASR } \\
(1 / 100000)\end{array}$ & $\begin{array}{c}\text { WASR } \\
(1 / 100000)\end{array}$ \\
\hline National & 21626 & 2.6 & 2.5 \\
Urban areas & 10950 & 2.5 & 2.4 \\
Rural areas & 10676 & 2.7 & 2.6 \\
Eastern regions & 7314 & 2.1 & 2 \\
Central regions & 8285 & 3.1 & 3 \\
Western regions & 6027 & 2.9 & 2.8 \\
\hline
\end{tabular}

areas (NBS, 2014b). Western China is the less developed region, with a vast area of 54.1 million square kilometres, some of which is remote and contains a large proportion of ethnic minorities. It has a GDP of US $\$ 2354$ (Goss et al., 2014; Jian et al., 2010), and only $43.8 \%$ of its population are urban residents (NBS, 2014b).

In China, $50.6 \%$ of the population lived in urban areas in 2011. Moreover, the government plans to accelerate urbanisation to increase this by $2.9 \%$ annually (WHO, 2011b). With rapid urbanization and economic growth, more and more rural labour has entered the cities seeking employment opportunities. Based on the National Bureau of Statistics (NBS) census data, the estimated number of rural migrant workers (farmers who migrate to urban areas for work) was 20 million in 1990, 45 million in 1995, and 79 million in 2000 (Qin et al., 2014). By 2013 this number had grown to 269 million (NBS, 2014a). Millions of rural people in the central and western regions have flooded into eastern industrial centres to work and this pattern of internal movement accounts for $72.4 \%$ of all migrant workers (Yao and Ren, 2007). The economic growth, urbanisation and internal migration have brought lifestyle changes with increasingly westernised dietary habits, and increases in smoking rates, infectious diseases rates, and environmental pollution (Tsu et al., 2013; Goss et al., 2014). These changes have contributed to the increasing importance of non-communicable diseases, including cervical cancer, in the health landscape of China (Goss et al., 2014).

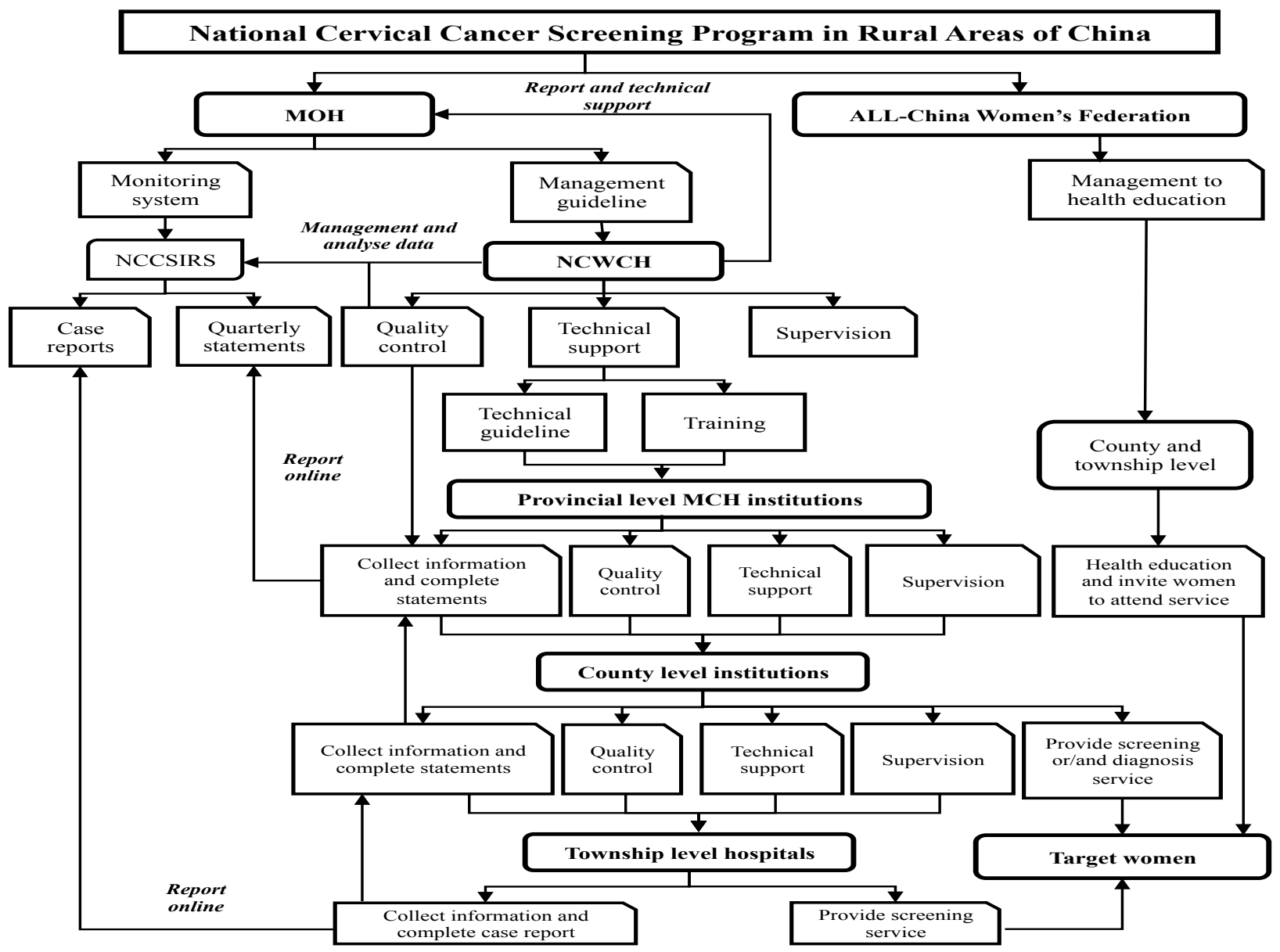

Figure 3. Responsibility of Different Institutions at All Levels in Implementation of the NCCSPRA 
These rapid, large scale social changes have increased social disparities between urban, rural and migrating populations in China. Roughly $44 \%$ of rural people live without access to sanitation facilities, compared with $26 \%$ of urban people (WHO, 2012). Rural people continue to have poorer education and employment, lower socioeconomic status and poorer access to health services (Goss et al., 2014; Jian et al., 2010). For example, there are 15.8 registered doctors or nurses per 1000 people and 6.88 hospital beds per 1000 population in urban areas, compared with 5.9 doctors per 1000 people and 3.11 hospital beds per 1000 population in rural areas (NHFPC, 2013a). These issues are risk factors for developing cervical cancer and hinder patients' access to cancer care. Consequently they are likely to have cancer diagnosed at a later stage, leading to restricted treatment options and poorer cancer outcomes (Jia et al., 2013; Thulaseedharan et al., 2013; Tsu et al., 2013; Goss et al., 2014).

Substantial social and health inequalities also exist between the more developed eastern regions, developed central regions and less developed western regions. There are 11.2 registered doctors or nurses per 1000 people in eastern China, compared with 6.6 per 1000 in rural western China (NHFPC, 2013a). The inequities also exist for rural migrant workers. Although the data from the China Health Statistics Yearbook in 2013 shows that $98.3 \%$ of the rural population are covered by the New Rural Cooperative Medical System (NRCMS) (NHFPC, 2013a), only 16.7$26.6 \%$ of rural migrant workers have access to Urban Employee Basic Medical Insurance (UEBMI) and Urban Resident Basic Medical Insurance (URBMI) (Qin et al., 2014). Due to the lack of insurance coverage, high outof-pocket expenditure is required (Song et al., 2010) and this combined with a tendency to rely on self-medication (self-diagnosis and self-treatment) (Liang et al., 2010) contributes to the situation where $53 \%$ of migrant workers do not access a doctor when they become ill (Shao et al., 2013). It can be argued that all the geographical and socioeconomic disparities above, together with the lack of an equitable national social-support system (Goss et al., 2014), has led to the differences observed in incidence and mortality in cervical cancer between different regions within China.

\section{Population-based cervical cancer screening program in China}

In China, the maternal child health $(\mathrm{MCH})$ system plays a key role in delivering organized cervical cancer screening. Hence to understand the national populationbased cervical cancer screening program, the structure of the MCH system and its role in delivering organized cervical cancer screening is described.

The MCH system was one of the first public health service systems established following the founding of the Peoples Republic of China in 1949. It consists of maternal and child health professional institutions at urban and rural primary health care facilities. In China, maternal and child health institutions are government-organized, notfor-profit public institutions with the roles of organizing, managing and providing women and children's health services. This includes both individual treatment services, but also the design and implementation of prevention activities aimed at individuals and populations. This system has played a vital role in improving women and children's health in China (MOH, 2012c). The Maternal Mortality Rate fell markedly, from 80/100,000 in 1991 to $24.5 / 100,000$ in 2012 (NHFPC, 2013a). The Infant Mortality Rate in 2012 was $10.3 \%$, down by $79.4 \%$ and $68.0 \%$ respectively from 1991 and 2000 . The under-five mortality rate was $13.2 \%$ in 2012 , down by $78.4 \%$ and $66.8 \%$ respectively from 1991 and 2000 (NHFPC, 2013a).

Within the prevention and treatment activity for common gynaecological diseases, cervical cancer screening has become the most significant routine work of $\mathrm{MCH}$ professional institutions (e.g. $\mathrm{MCH}$ hospitals) $(\mathrm{MOH}, 2006)$. In the 1970 s and $1980 \mathrm{~s}$, in urban areas organized cervical cancer screening was mainly carried out in state owned enterprises especially in the textile sector, as a free service for female workers. In rural areas, free or low-price pap-smear screening was delivered for female villagers by the $\mathrm{MCH}(\mathrm{MOH}, 2006)$. Because of the ongoing implementation of the strategies for prevention of common gynaecological diseases both in urban and rural areas, many regions such as Shanghai, Beijing and Jingan county in Jiangsu province have been very successful in reducing cervical cancer incidence ( $\mathrm{MOH}, 2006)$.

However the economic reforms in the early $1980 \mathrm{~s}$ and associated profit driven enterprises have led to a decline in corporate funds for cervical cancer screening (Shi, 2003; Shen, 2007), placing more burden on the government funded system. In addition since China's economic reforms in the 1980s, MCH institutions have been forced to be increasingly profit-oriented due to inadequate government funding and support. The marketoriented approach of providing $\mathrm{MCH}$ services conflicts with the public function of MCH services. The position and importance of maternal and child health services is changing due to the impact of the market economy. Given the limited financial support provided by the government, $\mathrm{MCH}$ services have changed with an emerging emphasis on "treatment over prevention" and on "paid over non-paid services". The combination of inadequate government funding and the imposition of client fees for $\mathrm{MCH}$ services has negatively impacted the utilization and access to $\mathrm{MCH}$ services in low income population groups, (MOH et al., 2006).

In 2009 , in order to reduce regional disparities in cervical cancer burden, China's government launched the NCCSPRA. It was the first time that the Chinese government had proposed to gradually widen access in rural areas to cervical cancer screening services and it represented a step towards nationwide provision of cervical cancer screening (Lancet, 2009).

The MCH institutions at all levels are responsible for implementation of the program, providing technical services support for health education, consultation, and screening and diagnosis services (Figure 3 ). They also collect, summarize, analyse and report related information, develop health education resources about prevention and control of cervical cancer, organize the expert group to 
carry out technical guidance and quality control, and follow-up positive cases. The health institutions at the county level and above are responsible for providing medical services for those suspected cases and feeding back the results of diagnosis to the institutions where the cases originated. The Women's Federations at all levels are responsible for organizing the women to participate in cervical cancer screening (MOH, 2009).

The township level hospitals are responsible for collection and fixation of the smear, collection of Human Papillomaviruses (HPV) DNA specimen or providing visual inspection with acetic acid or Lugol's iodine (VIA/ VILI) tests. The health institutions at the county level and above are responsible for cytology reading, HPV testing, providing colposcopy and pathologic examination $(\mathrm{MOH}$, 2009, 2012a; NHFPC, 2014).

From 2009 to 2011, 11.69 million rural women aged between 35 and 59 years in 221 pilot counties, covering 31 provinces and autonomous regions received this free service (MOH, 2012b). By design, the pilot counties were concentrated in China's less developed central and western regions. Among the 221 pilot counties, $50 \%$ of the counties are in western regions and $35 \%$ are in central regions (MOH, 2009).

Although the screening service in this program was provided free to all target women, the funds allocated from government didn't include funds for training service providers, follow-up or treatment services. Financial support for treatment services included only insurance NRCMS added cervical and breast cancer treatment to the scope of major illness protection in 2011 and special one-off funds for those most vulnerable were provided by The All China Women's Federation (MOH, 2012b).

Following World Health Organization (WHO) recommendations (WHO, 2007) and considering the demography and the financial situation in China, beginning in 2012, the screening target age was changed from 35-59 to $35-64$ years. The number of women eligible to access the free service increased to 30 million women from rural areas across 1185 counties in 2012-2014 (MOH, 2012a).

The cervical cancer screening program in rural areas of China has been operating now for almost 5 years. However, there remain some important challenges to improve its outcomes.

\section{Low screening coverage rate}

WHO recommends that high coverage, around $80 \%$ of the population at risk of cervical cancer, is an important factor for a successful screening program (WHO, 2006). Analysis of the cervical screening program in Mexico indicates that despite the implementation of a national screening program, a steady unchanging rate of mortality of 16/100,000 over 35 years was observed; principally due to factors associated with screening coverage and quality (Lazcano-Ponce et al., 1999; Lazcano-Ponce et al., 2008). A decrease in cervical cancer mortality has also been shown to be directly associated with coverage and participation rate in developed nations (IARC, 2005). It has been shown that for each unit of increase in screening coverage, the rate of cervical cancer mortality decreases by 0.07 (Lazcano-Ponce et al., 2008). Other data indicates that achieving a coverage rate of $25 \%$ is associated with a reduction in life-years lost of $21-25 \%$, and with $100 \%$ coverage the reduction in life-years lost could be $84-99.9 \%$ (IARC, 2005).

In China the total number of 35-64 year-old rural women is 156 million $(\mathrm{MOH}, 2013)$ and hence the 30 million target set in the national rural program only represents a screening coverage of $19 \%$ of eligible rural women. For this reason, increasing the screening coverage of rural women in China must be a priority.

\section{Shortage of qualified health care personnel}

Despite the Chinese government prioritizing increases in the quality and technical capacity of public health personnel over the past few decades (WHO, 2011) the issues of shortage of trained health care personnel and their availability in rural areas still remain. According to a report investigating resources and the operational situation of $\mathrm{MCH}$ institutions that covered $99.7 \%$ of $\mathrm{MCH}$ institutions, in county level $\mathrm{MCH}$ institutions which constitute the main implementers of the national rural screening program, $70.4 \%$ of service providers had education levels below bachelors degree, $28.5 \%$ had a bachelor degree and only $1 \%$ had a Masters or higher degree. $64.8 \%$ of service providers had only a primary technical qualification or no qualification (NCWCH, 2014).

In addition, qualified health workers are not well distributed across the country. Due to an inability to attract and retain qualified health workers, rural health systems especially in resource-poor areas, lose experienced health professionals to hospitals in urban areas (WHO \& China National Health Development Research Centre, 2012). A shortage of service providers poses a significant barrier to the delivery of quality cervical cancer screening services (IARC, 2005; WHO, 2006).

\section{Insufficient compensation from the government}

In China, one limitation of the current program is that although the target women receive a free screening service, the additional funds from the program only provide the costs for screening tests and diagnosis (MOH, 2009, 2012b; NHFPC, 2013b, 2014). This means that management organizations and hospitals which are responsible for organizing women, providing screening services, follow-up, and health education have to finance these related expenditures from their own operational budgets. Although the local governments are given the responsibility of financing the management of the program ( $\mathrm{MOH}, 2009)$, they are seldom able to raise revenue through taxes to finance public health services, especially in resource-poor areas. Moreover, compared with other health issues like maternal mortality, cervical cancer prevention is not deemed a priority issue in these regions (Goss et al., 2014). Thus, many implementation organizations and hospitals have insufficient resources for organizing women, training personnel, equipment for screening and diagnosis, follow-up, health education, and screening service quality control. At the county level, $41.7 \%$ of $\mathrm{MCH}$ institutions are either in a state of balanced budget or in deficit. Only $7.2 \%$ of county level $\mathrm{MCH}$ institutions had equipment for pathologic examination 
Jiangli Di et al

and $24.9 \%$ had equipment for staining or reading cervical smears slides and $78.8 \%$ had equipment for colposcopy (NCWCH, 2014). These figures suggest that shortage of funds for comprehensive implementation of the program remain a challenge for the current program to meet its goals. Due to this lack of management funds for the program, low participation rates (Xia et al., 2012; Jia et al., 2013), low capacities of service providers (Zhu, 2011; Xia et al., 2012), subsequent poor quality of services (Chen, 2009), and low rates of follow-up for positive screening results (Zhou et al., 2011) have already emerged in some program areas.

\section{Conclusion}

As the largest and most populous of the low to middle income countries in the world, China carries a large burden of cervical cancer (NCC et al., 2012; 2013). Although reducing the gap in inequality in health between rural and urban areas has been a focus of the Chinese government's health reform efforts since 1997, (Jian et al., 2010; WHO, 2011a), due to geographical and socioeconomic inequities (Jian et al., 2010; WHO, 2012; Goss et al., 2014), disparities in cervical cancer burden between different regions still persist (NCC et al., 2013). In order to reduce the high burden of cervical cancer in China, the Chinese government has implemented several important measures, including a national cervical cancer screening program in rural areas of China since 2009. Although this current program has achieved some important results in improving detection of cervical cancer or pre-cancer lesions (MOH, 2012b), the benefits of the program have not been fully realised. Despite the large scale investment made through development and implementation of NCCSPRA, figures presented in this paper suggest an overall increasing trend in both incidence and mortality rates. This increase may relate to the relatively short time since initial roll out (5 years), and to the weak quality of cervical cancer registration data (NCC et al., 2013). This situation might also be due to factors associated with low coverage rate $(\mathrm{MOH}, 2013)$, shortage of qualified health care personnel (MOH, 2013; NCWCH, 2014) and insufficient compensation from the government $(\mathrm{MOH}$, 2009, 2012b; NHFPC, 2013b, 2014), with a subsequent low participation rate (Jia et al., 2013; Xia et al., 2012) and poor quality of screening test, diagnosis and treatment, and follow-up for positive screening results (Chen, 2009; Zhou et al., 2011).

Hence, to improve the delivery and outcomes for cervical cancer care and narrow the inequalities between different regions in China the following key factors need consideration: reducing disparities in health care access, collecting accurate and broadly representative data in cancer registries, expanding target population size and enhancing the allocation of government funding for training, health education, quality control and follow-up.

\section{References}

Chen HY (2009). Obvious bottleneck of cervical cancer screening. China Hospital CEO, 20, 28-29.
Chen WQ, Zheng RS, Zhang SW, et al (2014). Annual report on status of cancer in China, 2010. Chinese J Cancer Res, 26, 48-58.

Goss PE, Strasser-Weippl K, Lee-Bychkovsky BL, et al (2014). Challenges to effective cancer control in China, India, and Russia. Lancet Oncol, 15, 489-538.

IARC (2005). IARC handbooks of cancer prevention (Vol. 10). Geneva: IARC Press.

IARC (2012a). Cervix uteri - estimated incidence, all ages. retrieved september 5, 2014, from http://globocan.iarc.fr/ old/summary_table_pop-html.asp?selection $=39160 \&$ title $=$ China \&se $=2 \&$ type $=0 \&$ window $=1 \&$ sort $=0 \&$ submit $=\% \mathrm{C}$ $2 \% \mathrm{~A} 0$ Execute $\% \mathrm{C} 2 \% \mathrm{~A} 0$

IARC (2012b). GLOBOCAN 2012: Estimated cancer incidence, mortality and prevalence worldwide in 2012. retrieved september 5, 2014, from http://globocan.iarc.fr/Pages/ fact_sheets_cancer.aspx?cancer=cervix

Jia Y, Li S, Yang R, et al (2013). Knowledge about cervical cancer and barriers of screening program among women in Wufeng County, a high-incidence region of cervical cancer in China. Plos One, 8, 67005.

Jian WY, Chan KY, Reidpath DD, et al (2010). China's ruralurban care gap shrank for chronic disease patients, but inequities persist. Health Affairs, 29, 2189-96.

Lancet T. (2009). Women's health in rural China. Lancet, 374, 358.

Lazcano-Ponce E, Moss S, de Ruiz PA, et al (1999). Cervical cancer screening in developing countries: Why is it ineffective? the case of mexico. Archives Med Res, 30, 240-250.

Lazcano-Ponce E, Palacio-Mejia LS, Allen-Leigh B, et al (2008). Decreasing cervical cancer mortality in mexico: effect of Papanicolaou coverage, birthrate, and the importance of diagnostic validity of cytology. Cancer Epidemiol Biomarkers Prev, 17, 2808-17.

Liang W, Zheng J, He L, et al (2010). Research on health service demands and utilization of rural migrant workers in Taiyuan. China Health Resour (in Chinese), 13, 67-69.

$\mathrm{MOH}$. (2006). Results assembly about research on policy of women and children's health. beijing: people's medical publishing house.

MOH. (2009). Management plan for rural areas cervical cancer and breast cancer screening examination program. retrieved june 24, 2009, from http://www.moh.gov.cn/fys/ s7900/200906/cd3c33a7ad624a50b8100b262041dabe.shtml

MOH (2012a). Notification about carry out major women and children's public health program in 2012. ([2012]79). Beijing: Ministry of Health of the People's Republic of China Retrieved from http://www.mchscn.org/Article_Show. asp?ArticleID=470.

MOH (2012b). Record of process of major women and children's public health program in press conference. beijing: record of process of major women and children's public health program in press conference.

MOH (2012c). Report on women and children' health development in China (2011). beijing: ministry of health of the people's republic of China.

MOH (2013). China's health statistics yearbook 2013. Beijing: Peking Union Medical College Press.

MOH, UNICEF, WHO, et al (2006). Jiont review of the maternal and child survival strategies in China. Beijing: Ministry Of Health Of The People's Republic of China.

NBS (2014a). 2013 National economic and social development statistics bulletin. Beijing: National Bureau Of Statistics.

NBS (2014b). National data. retrieved october 12 2014, from http://data.stats.gov.cn/workspace/index?m=hgnd

NCC, DPCB, NHFPC (2012). Chinese cancer registry annual 
report 2012. Beijing: Military Medical Science Press.

NCC, DPCB, NHFPC (2013). Chinese cancer registry annual report 2013. Beijing: Military Medical Science Press

NCWCH CC (2014). The report of resources and operation situations of $\mathrm{MCH}$ institutions in 2013 Beijing: National Center For Women And Children's Health, China CDC.

NHFPC (2013a). China health statistics yearbook 2013.

NHFPC (2013b). Notification about carry out major women and children's public health program in 2013. ([2013]65). Beijing: Notification about carry out major women and children's public health program.

NHFPC (2014). Notification about carry out major women and children's public health program in 2014. ([2014] 84). Beijing: Notification about carry out major women and children's public health program.

NOCPC, NCCR, DPCB (2008). Chinese cancer registry annual report 2004. Beijing: Beijing Union Medical University Press.

NOCPC, NCCR, DPCB (2010). Chinese cancer registry annual report 2010. Beijing: Military Medical Science Press.

Qin XZ, Pan J, Liu GG (2014). Does participating in health insurance benefit the migrant workers in China? An empirical investigation. China Econ Rev, 30, 263-278.

Shao S, Zhao F, Wang J, et al (2013). The ecology of medical care in Beijing. PloS One, $\mathbf{8}, 82446$.

Shen J (2007). Study on the special labour protection of women employees. Xiamen.

Shi JF, Canfell K, Lew JB, et al (2012). The burden of cervical cancer in China: Synthesis of the evidence. Int J Cancer, 130, 641-52.

Shi MX (2003). Research on the legislation issue of female workers' labour protection. China Safety Scie J, 1-4.

Song J, Leng M, Meng F, et al (2010). Research on health service utilization of rural migrant workers in Nanjing. Chinese Primary Health Care (in Chinese), 24, 10-11.

Thulaseedharan JV, Malila N, Hakama M, et al (2013). Effect of screening on the risk estimates of socio demographic factors on cervical cancer - a large cohort study from rural India. Asian Pac J Cancer Prev, 14, 589-94.

Tsu VD, Jeronimo J, Anderson BO (2013). Why the time is right to tackle breast and cervical cancer in low-resource settings. Bulletin of the World Health Organization, 91, 683-90.

WHO (2006). Comprehensive cervical cancer control A guide to essential practice. Geneva: WHO press.

WHO (2007). Cancer control: knowledge into action, WHO guide for effective programmes, early detection. Geneva: WHO Press.

WHO (2011a). Country health information profiles: China. retrieved september 29, 2014, from http://www.wpro.who. int/countries/chn/5CHNpro2011_finaldraft.pdf

WHO. (2011b). The world factbook: China. retrieved september 23, 2014, from https://www.cia.gov/library/publications/ the-world-factbook/geos/ch.html

WHO (2012). China. retrieved october 13, 2014, from http:// www.wpro.who.int/countries/chn/en/

WHO, China National Health Development Research Centre. (2012). Health service delivery profile: China. retrieved $29^{\text {th }}$, Sep, 2014, from http://www.wpro.who.int/health_services/ service_delivery_profile_china.pdf

Xia JH, Luo XP, Xue SH, et al (2012). The obstacles of women in rural areas taking part in screening of cervical cancer and sgrategies. China J Women Child Health, 3, 363-6.

Yao HQ, Ren ZZ (2007). Report on economic development in western regions of China. Beijing: Social Sciences Academic Press.

Zhou JY, Qiu LP, Liu L, et al (2011). Analysis of inf luencing factors on compliance with colposcopy in cervical cancer screening project in daxing district, beijing city. Chinese $J$ Health Educat, 27, 498-501.

Zhu LH (2011). Impact of screening tests of cervial cancer and breast cancer screening in rural areas to implementation of program. Maternal Child Health Care China, 26, 5673-5675. 